\title{
PATOLOGÍA ORAL EN EL PACIENTE VIH POSITIVO
}

El SIDA se caracteriza por ser una enfermedad que afecta al sistema inmunitario, lo que conlleva a estos pacientes a desarrollar infecciones oportunistas y procesos neoplásicos ${ }^{1}$. La cavidad oral constituye el sustrato sobre el que pueden asentar gran cantidad de lesiones "oportunistas" en pacientes con infección VIH.

La tabla I recoge las afecciones orales que de una u otra forma se pueden ver en pacientes serologicamente positivos al virus $\mathrm{VIH}^{2}$.

- Grupo 1.- Lesiones orales fuertemente asociadas a la infección por VIH:

- Candidiasis: Eritematosa, Pseudomembranosa.

- Leucoplasia vellosa.

- Sarcoma de Kaposi.

- Linfoma No Hodgkin.

- Enfermedad Periodontal: Eritema gingival lineal, Gingivitis ulcerativa necrotizante, Periodontitis ulcerativa necrotizante.

- Grupo 2.- Lesiones orales asociadas con menos frecuencia a la infección VIH:

- Infecciones bacterianas: Micobact. avium intracelular, M. tuberculosis.

- Hiperpigmentación melánica.

- Estomatitis ulcerativa necrotizante.

- Enfermedades de glándulas salivales: Xerostomía por disminución del flujo, Inflamación uni o bilateral de glándulas mayores.

- Púrpura trombocitopénica.

- Ulceraciones NOS.

- Infecciones víricas excluyendo el virus de Epstein-Barr:

Herpes Simple, virus del papiloma humano (condiloma acuminado, hiperplasia focal epitelial verruga vulgar).

Virus Varicela-Zoster.

- Grupo 3.- Lesiones orales observadas en infección por VIH:

- Infecciones bacterianas: Actinomices israelí, E.coli, K. pneumonie.

- Enfermedad por arañazo de gato.

- Reacciones por fármacos: ulceras, eritema multiforme, liquenoide, epidermolisis tóxica.

- Angiomatosis epitelioide bacilar.

- Infecciones por hongos (excepto candida): Cryptococcus neoformas, Geotrichum candidum, Mucoreaceae, Histoplasma capsulatum y Aspergillus flavus. 
En esta clasificación, avalada por la OMS, se diferencian tres grupos de lesiones orales. Por un lado, aquellas patologías que están fuertemente asociadas a la infección VIH. Un segundo grupo engloba las lesiones que se asocian a esta enfermedad con una menor frecuencia y el tercer grupo, constituye un cajón de sastre en el que quedan recogidas otras lesiones orales que pueden darse en estos pacientes.

Para el clínico practico, es importante tener presentes estas afecciones cuando se valoran a un posible paciente VIH/SIDA. Esto, se fundamenta en dos aspectos; en muchos casos, estas lesiones representan la primera manifestación de su infección por el virus del SIDA y pueden ayudarnos a realizar el diagnostico ${ }^{1}$. Por otra parte, La aparición de determinadas lesiones tiene un importante valor pronóstico para el paciente, apareciendo con mayor frecuencia con cargas virales $>3000$ copias $/ \mathrm{ml}$ y con cifras de CD4 < 200 células $/ \mathrm{mm}^{3} 3$.

El actual tratamiento antirretroviral de gran actividad (TARGA), ha representado importantes cambios en la evolución de esta enfermedad y en la consiguiente reducción de las infecciones y enfermedades oportunistas ${ }^{4}$.

De todas formas, no se debe bajar la guardia y conviene pensar en estas afecciones, diagnosticarlas, relacionándolas con la enfermedad de base (VIH/ SIDA) y tratarlas de forma adecuada. Puede ser aconsejable realizar exámenes orales periódicos a los pacientes VIH/SIDA, encaminados a monitorizar la progresión de su enfermedad y a aliviar sus enfermedades oportunistas en esa localización. Por último, es necesario conseguir una buena adherencia a los tratamientos antirretrovirales, lo que repercutirá no solo en una mejora en la evolución de la enfermedad, sino también en la reducción de las enfermedades oportunistas, incluidas las lesiones orales.

\section{REFERENCIAS BIBLIOGRÁFICAS}

1. Camino X, Arrizabalaga J, Avellanal D. Infecciones virales. Citomegalovirus, herpes simple, virus JC, VHH-8. En: Soriano V y col. Manual del SIDA. $6^{\text {a }}$ edic. Barcelona: Public. Permanyer. 2005; 149-166.

2. Velasco E, Bullón P. Clasificación de las lesiones orales asociadas a la infección por VIH. En: Velasco E y col. Odonto-estomatología y SIDA. Barcelona: Edit. Espaxs SA, 2002; 165-183.

3. Tappuni AR, Flemming GJ. The effect of antiretroviral therapy on the prevalence of oral manifestations in HIV-infected patients: a U K study. Oral Surg Oral Med Oral Pathol Oral Radiol Endod. 2001; 92(6): 623-8.

4. Patton LL, McKaig R, Straauss R, Rogers D, Enron JJ. Changing prevalence of oral manifestations of human inmunodeficiency virus in the era of protease inhibitor therapy. Oral Surg Oral Med Oral Pathol Oral Radiol Endod. 2000; 90: 299-304.

Andrés Martínez Cordero Servicios Medicos C.P. Villabona Email: andresmc@saludalia.com 